\title{
Caudate nucleus-dependent navigation strategies are associated with increased risk-taking and set-shifting behavior
}

\author{
Étienne Aumont, ${ }^{1}$ Caroll-Ann Blanchette, ${ }^{1}$ Veronique D. Bohbot, ${ }^{2}$ and Greg L. West ${ }^{1}$ \\ ${ }^{1}$ Centre de Recherche en Neuropsychologie et Cognition, University of Montreal, Montreal, Quebec H3C 3J7, Canada; ${ }^{2}$ Douglas Mental \\ Health University Institute, Department of Psychiatry, McGill University, Verdun, Québec H4H 1R3, Canada
}

\begin{abstract}
When people navigate, they use strategies dependent on one of two memory systems. The hippocampus-based spatial strategy consists of using multiple landmarks to create a cognitive map of the environment. In contrast, the caudate nucleusbased response strategy is based on the memorization of a series of turns. Importantly, response learners display more gray matter and functional activity in the caudate nucleus and less gray matter in the hippocampus. In parallel, the caudate nucleus is involved in decision-making by mediating attention toward rewards and in set-shifting by mediating preparatory actions. The present study, therefore, examined the link between navigational strategy use, that are associated with gray matter differences in the caudate nucleus and hippocampus, and decision-making and set-shifting performance. Fiftythree participants completed the 4 on 8 virtual maze, the lowa Gambling Task (IGT), the Wisconsin Card Sorting Test-64 (WCST-64), and a task-switching test. The results revealed that people who use response strategies displayed increased risktaking behavior in the IGT compared to the people using hippocampus-dependent spatial strategies. Response strategy was also associated with enhanced set-shifting performance in the WCST-64 and task-switching test. These results confirm that risk-taking and set-shifting behavior, that are differentially impacted by the caudate nucleus and hippocampus memory systems, can be predicted by navigational strategy.
\end{abstract}

Distinct memory systems are involved in navigation. The hippocampus supports spatial navigation which involves the formation of a cognitive map, allowing for the establishment of relationships between environmental landmarks for more flexible navigation (O'Keefe and Nadel 1978). In contrast, the caudate nucleus supports response learning which is critical for stimulus-response learning, allowing for the efficient memorization of a rigid sequence of movements (Packard and Knowlton 2002). Depending on the context, these independent memory systems can function in cooperation (Voermans et al. 2004; Shohamy and Wagner 2008; Wimmer and Shohamy 2012; Wimmer et al. 2014; Müller et al. 2018), in competition (Packard 1999; Poldrack et al. 2001; Lee et al. 2008; Gardner et al. 2018) or in parallel (Doeller et al. 2008) for the ability to influence behavior. When competition between the two systems exists over time, changes in brain structures involved in these two systems occurs (Iaria et al. 2003; Bohbot et al. 2007; Konishi and Bohbot 2013; West et al. 2018). One way to measure the existence of competition between both memory systems is to measure navigation strategy use (Packard 1999; Bohbot et al. 2004; Lee et al. 2008). When people use spatial navigation strategies, they recruit the hippocampus, displaying more functional activity in this structure (Iaria et al. 2003). People who use spatial strategies also display increased gray matter in the hippocampus (Bohbot et al. 2007). In contrast, people who use response navigational strategies recruit the caudate nucleus, and display more gray matter in this structure (Iaria et al. 2003; Bohbot et al. 2007; West et al. 2018). Supporting these observations, rodents trained to navigate using spatial strategies displayed increased gray matter in the hippocampus, whereas rodents trained to use response strategies displayed increased gray matter

\section{Corresponding author: gregory.west@umontreal.ca}

Article is online at http://www.learnmem.org/cgi/doi/10.1101//m.048306.118. in the caudate nucleus (Lerch et al. 2011). Navigational strategies are therefore well-established predictors of the ratio of functional activity and gray matter volume between the hippocampal and caudate nucleus memory systems, where response learning is associated with lower gray matter in the hippocampus and higher gray matter in the caudate nucleus.

Both the hippocampus and caudate nucleus memory systems have different anatomical connections to the rest of the brain. Therefore, in addition to its impact on brain structures, navigational strategies are associated with different cognitive processes (Bohbot et al. 2007; Konishi and Bohbot 2013; Shohamy and Turk-Browne 2013; Dahmani and Bohbot 2015). As such, hippocampus and caudate nucleus-dependent strategies may lead to differences in cognitive performances in different domains. Notably, healthy older adult response learners display lower performance on the Montreal Cognitive Assessment compared to spatial learners (Bohbot et al. 2007; Konishi et al. 2017). In younger adults, response learners were shown to have significantly more lifetime use of tobacco, and are significantly more likely to regularly use cannabis (Bohbot et al. 2013) and showed increased consumption of action video games (West et al. 2015, 2018). In parallel, the caudate nucleus also has an important role in mediating executive functions, as evidenced by mediation of prefrontal activity through dopaminergic mesocortical pathway have been found (Cools 2011; Cools and D'Esposito 2011). Specifically, the caudate nucleus allows action preparation, reversal learning-the acquisition of

(C) 2019 Aumont et al. This article is distributed exclusively by Cold Spring Harbor Laboratory Press for the first 12 months after the full-issue publication date (see http://learnmem.cshlp.org/site/misc/terms.xhtml). After 12 months, it is available under a Creative Commons License (AttributionNonCommercial 4.0 International), as described at http://creativecommons .org/licenses/by-nc/4.0/. 
new learning rules in conflict with a previous set of learning rulesand is linked to an attentional bias directed toward positive feedback (Balleine et al. 2007; Monchi et al. 2007; Shi et al. 2018).

\section{Risk-taking}

Value-based decision-making begins with selection of one action among many that are available to an individual. This selection is based on the perceived value of each action available to the individual. In the context of value-based decision-making, risk-taking is defined as the propensity to choose an action that generates a higher reward but also has a higher probability of producing a disadvantageous result (Rangel et al. 2008). The caudate nucleus has a central role in increased risk-taking behavior through actionreward encoding (Packard and Knowlton 2002; Samejima et al. 2005; Johnson et al. 2007). Further, this structure is associated with reward-seeking behavior, increasing the attention directed toward positive feedback, while reducing attention directed toward negative feedback and increasing motivation directed toward rewarding stimuli (Robbins and Everitt 2002; Everitt and Robbins 2005; Baler and Volkow 2006; Brody et al. 2006; Balleine et al. 2007; Volkow et al. 2007). Approximately 10\% of Parkinson's patients who take dopaminergic medication, which causes dopamine liberation in the striatum displayed increased risk-taking behavior, while causing increased impulsivity and addiction behavior, providing further evidence of the role of the caudate nucleus in risktaking (Frank et al. 2007; Vo et al. 2011; Callesen et al. 2013). Based on this evidence, we predicted that response learners, who display increased functional activity and gray matter in the caudate nucleus and lower functional activity in the OFC compared to spatial learners, would display increased risk-taking behavior in a decision-making task (Iaria et al. 2003; Bohbot et al. 2007; Dahmani and Bohbot 2015). To measure risk-taking behavior, we used the Iowa Gambling Task (IGT). The IGT requires participants to select cards among four decks, two which are globally advantageous, but offer little reward, and two which are globally disadvantageous, but offer higher rewards. Therefore, the IGT measures the propensity to take risks (Bechara et al. 1994; Buelow and Suhr 2009; Buelow and Blaine 2015). We therefore predicted that response learners would display increased risk-taking by choosing more cards from disadvantageous but higher-reward decks.

\section{Set-shifting}

In contrast to risk-taking behavior, increased gray matter and activity in the caudate nucleus is associated with better performance in certain cognitive tasks. There is ample evidence that the caudate nucleus is involved in set-shifting, defined as the ability to shift from one rule to another. This shift can be either learned through feedback or explicitly stated within a task. This can be measured by sorting tasks, in order to quantify the ability to reverse previously learned rules, and by task-switching tests that measure performance costs associated with predictable, explicit rule changes (Milner 1963; Wylie and Allport 2000; Greve 2001; Monsell 2003).

Rogers et al. (2000) found that while the prefrontal cortex was essential for initial acquisition in a sorting task, the caudate nucleus was recruited when a rule change occurred. This suggested that the caudate nucleus is specifically involved in reversal learning through modulation of prefrontal cortex activity during rule change detection. Further supporting this idea, several studies have identified that the caudate nucleus is recruited both when receiving negative feedback and after the execution of a novel action, suggesting that the caudate might allow action preparation, impacting reversal learning (Monchi et al. 2001, 2006; van Schouwenburg et al. 2010; Provost et al. 2012). Because of this, the caudate nucleus could play a role in action planning and reversal learning, allowing set-shifting in both types of processes. Further, decreased activity in the caudate nucleus system has been associated with decreased setshifting performance across several experiments. First, decreased reversal learning abilities found in obsessive-compulsive individuals has been associated to a mesocortical dopamine deficit, which is mediated by the caudate nucleus (Cools 2011; Cools and D'Esposito 2011; Vaghi et al. 2017). The reversal learning deficit and low task-switching performance associated with parkinsonism has also been attributed with the mesocortical pathway, however, these deficits are reduced when dopamine medication is taken (Hayes et al. 1998; Cools et al. 2001, 2003; Monchi et al. 2004, 2007; Cools 2006; Nagano-Saito et al. 2008; Aarts et al. 2014; MacDonald et al. 2014). Finally, functional connectivity between the caudate nucleus and the prefrontal cortex has been found to be a reliable indicator of observed task-switching deficits found in Parkinson patients (Gul et al. 2017).

Based on this evidence, we predicted that caudate nucleusdependent response learners would display enhanced set-shifting performance compared to spatial learners who, in contrast, display lower functional activity and gray matter in the caudate nucleus. To measure set-shifting performance we used the Wisconsin Card Sorting Test-64 cards version (WCST-64) (Greve 2001) and task-switching test (Stoet et al. 2013). The WCST is a task where participants have to sort cards according to basic characteristics. The correct characteristic to be used changes though the course of the task. Therefore, it measures the ability to learn and apply rules through changing contingencies. We predicted that response learners would display higher performance in the WCST through decreased perseverative errors and a higher chance of successfully completing the task. The task-switching test used measures action preparation and switching costs by asking participants to alternate between tasks that follow a predictable pattern. Switch costs are reflected as higher reaction times for trials where the rule is different to that of the previous trial. We therefore predicted that response learners would display lower switch cost across this task.

\section{Results}

\section{Navigation}

Among the 53 participants, 25 (five male) were classified as spatial learners, whereas 25 (seven male) were classified as response learners and three were unable reach criterion and were not included in analysis. Of those 25 spatial learners, 14 shifted to response strategy at some point in the task. This is common, as the task can be solved using either a spatial or response strategy. However, people who spontaneously begin the task using a spatial strategy and later shift display more gray matter and fMRI activity in the hippocampus compared to those who spontaneously adopt a response strategy (Bohbot et al. 2007; Iaria et al. 2003). The inter-rater reliability was high $\left(\kappa_{(50)}=0.960, P<0.0001\right)$. A third rater was consulted in the single case where the two initial raters were incongruent. The groups did not significantly differ in terms of age (spatial: $M=$ $22.68, \mathrm{SD}=3.91$ yr; response: $M=24.28, \mathrm{SD}=4.96 \mathrm{yr} ; t_{(48)}=1.266$, $P=0.212$ ) or education (spatial: $M=15.60, \mathrm{SD}=1.89$; response: $M$ $\left.=16.04, \mathrm{SD}=1.93 ; t_{(48)}=0.815, P=0.419\right)$ or $\operatorname{sex}\left(\chi^{2}(1, N=50)=\right.$ $0.439, P=0.508)$. As has been previously reported, response learners made significantly fewer probe errors associated with reduced landmark use during navigation: 22 response learners made no probe trial errors, whereas only eight spatial learners made no error $\left(\chi^{2}(1, N=50)=16.333, P<0.0001\right.$, Cramer's $\left.\phi=0.572\right)$ (Iaria et al. 2003; Bohbot et al. 2007; Konishi and Bohbot 2013; West et al. 2015, 2018; Drisdelle et al. 2017).

\section{lowa Gambling Task}

Spatial and response learners were compared over IGT raw and net scores. Raw scores for the IGT ranged from 250 to 4150 (from the 
initial 2000, spatial ranged from 1200 to 4150 and response, from 250 to 3750), whereas total net scores ranged from -32 to 96 (spatial ranged from -32 to 96 and response from -28 to 64 ). Spatial learners obtained significantly higher raw (spatial: $M=2762, \mathrm{SD}=$ 665.25; response: $M=2158, \mathrm{SD}=859.83 ; t_{(48)}=2.778, P=0.008$, Cohen's $d=0.802$ ) and total net scores (spatial: $M=35.28, \mathrm{SD}=$ 17.63; response: $M=10.48, \mathrm{SD}=12.80 ; t_{(48)}=2.846, P=0.006$, Cohen's $d=0.822$ ) than response learners in the IGT, response learners displayed higher risk-taking behavior compared to spatial learners (Fig. 1). This is considered to be large effect sizes according to Cohen (1977). No interaction between progress across blocks and strategies were found $\left(F_{(1)}=0.838, P=0.365\right)$.

\section{Wisconsin Card Sorting Test}

Spatial and response learners were compared on WCST-64 measures of the number perseveration errors and completion of task (dichotomic measure). The number of perseveration errors ranged from 3 to 23 errors (spatial ranged from 3 to 23 and response, from 3 to 19), and 29 out of 49 participants were able to complete all six sets in the task. Spatial learners made significantly more perseveration errors than response learners when controlling for education (spatial: $M=11.720, \mathrm{SD}=6.491$; response: $M=7.792, \mathrm{SD}=4.201$; $F_{(1)}=6.268, P=0.016$, $=0.118$ ) (Fig. 2). Also, spatial learners had a significantly reduced task completion frequency when compared to response learners (spatial: $44 \%$; response: $75 \% ; \chi^{2}(1, N=49)=$ $4.871, P=0.027, \phi=0.315$ ). Both of these results indicate that response learners were able to better adapt to changing rules, and therefore displayed better task performance. These effects are considered to be medium to large in size (Cohen 1977, pp. 286-287).

\section{Task-switching}

Both spatial and response learners were compared based on switch cost measure calculated from the task-switching test reaction times. Before any analyses, task-switching reaction time data were cleaned for outlying trials, defined as trials with reaction time outside of the $\pm 2.5 \mathrm{SD}$ interval from the reaction time average for that trial subtype. Four subtypes were used: shape block, filling block, switch trials (alternating block), and nonswitch trials (alternating block). Average reaction times on blocks 1 and 2 ranges from 373 to $796 \mathrm{msec}$ (spatial ranged from 373 to $796 \mathrm{msec}$ and response, from 401 to $599 \mathrm{msec}$ ), while trials in the mixed block could average between 692 and 1347 msec (spatial ranged from
659 to $1347 \mathrm{msec}$ and response, from 676 to $1232 \mathrm{msec}$ ). The highest number of errors reported out of the 160 trials was 10 . Switch cost ranged from -52 to $455 \mathrm{msec}$ (spatial ranged from 15 to 455 msec and response, from -52 to $277 \mathrm{msec}$ ). Spatial learners had significantly higher switch cost than response learners when controlling for age (spatial: $M=198.36, \mathrm{SD}=148.16$; response: $M=126.70$, $\left.\mathrm{SD}=88.41 ; F_{(1)}=4.312, P=0.043,=0.082\right)$ (Fig. 3$)$. This is a medium to large effect according to Cohen (1977, pp. 286-287). This means that response learners were less affected by rule changes throughout the task, resulting in reduced reaction time cost in response to rule changes.

\section{Discussion}

The present study strongly supports the notion that caudate nucleus-dependent navigation strategies are associated with increased risk-taking behavior and set-shifting performance. First, we observed increased risk-taking behavior in response learners as measured through both increased raw and net scores in the IGT. Next, we observed increased set-shifting performance in response learners as measured by decreased perseverative errors combined with an increased completion rate in the WCST-64 and a decreased switch cost in a task-switching test.

\section{Decision-making}

Response learners selected a significantly higher number of cards from disadvantageous decks in the IGT compared to spatial learners, a task where losses are presented concurrently with gains, which means that both gains and losses were presented at the same time. Therefore, performance on this task can be affected by a bias toward one of the two types of feedback. This suggests increased risk-taking behavior in response learners compared to spatial learners. The caudate nucleus has been shown to increase attention toward positive feedback and rewards (Robbins and Everitt 2002; Everitt and Robbins 2005; Baler and Volkow 2006; Brody et al. 2006; Balleine et al. 2007; Volkow et al. 2007). This could explain the relatively risk-adverse performance observed in spatial learners as they have been observed to have lower functional connectivity and gray matter in the caudate nucleus (Iaria et al. 2003; Bohbot et al. 2007; Dahmani and Bohbot 2015). Greater risktaking in response learners was also predicted by evidence that this group displays higher addiction-related behaviors when compared
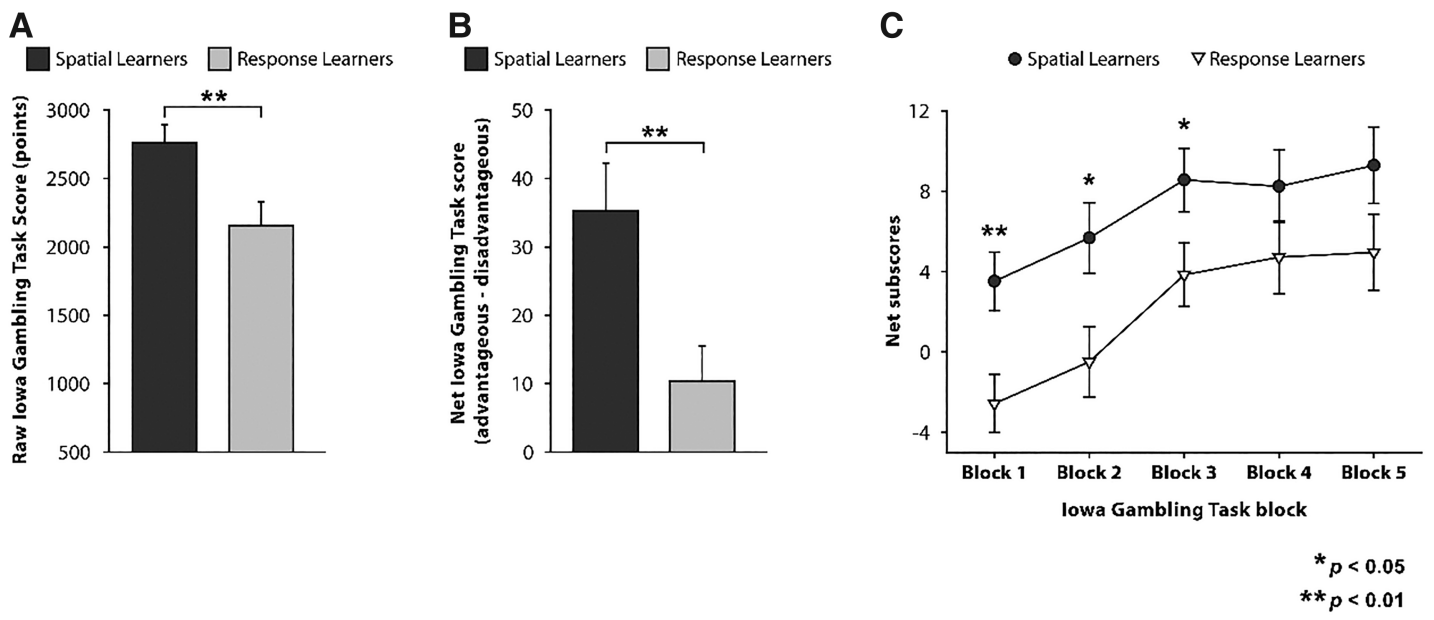

Figure 1. Results of the IGT. $(A, B)$ Spatial learners displayed significantly higher raw and net scores. (C) Progression through blocks was consistent between response and spatial learners. Spatial learners displayed significantly higher subscores within blocks 1, 2, and 3. Error bars represent the standard errors. 
A

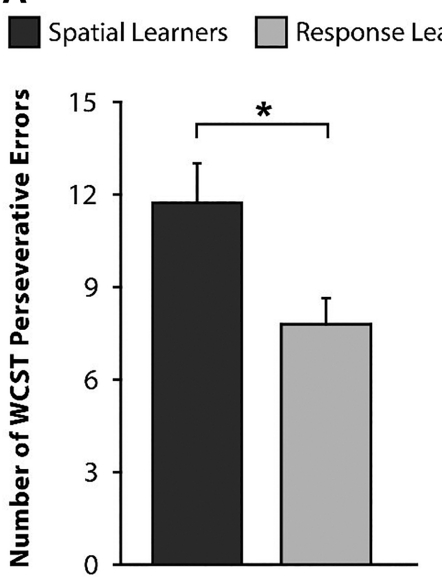

B
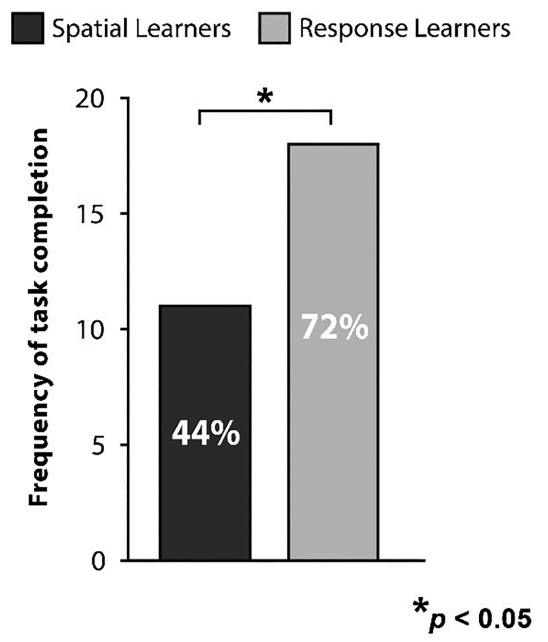

Figure 2. Results of the WCST-64. (A) Spatial learners made significantly higher levels of perseveration errors. $(B)$ Response learners were significantly more likely to successfully complete the task. Error bars represent the standard errors.

to spatial learners (Bohbot et al. 2013; West et al. 2015, 2018). Also, the striatal memory system is involved in habit formation and is theorized to be strengthened by reward related to substance use, meaning that stimulation of the striatum through addictionrelated behavior could increase the propensity to rely on response strategies (Goodman and Packard 2016). Our finding that response learners display increased risk-taking behavior is coherent with the strong relationship between risk-taking and addictions (Reynolds et al. 2013). Importantly, addiction is unlikely to explain our result as a third variable, as spatial and response learners did not differ on substance use and habitual video game playing. This suggests that the use of caudate nucleus-based memory system, which is engaged in both reward-seeking and response navigation strategies, is more likely to explain our results. One limit of the IGT, however, is that disadvantageous decks are associated with higher rewards, this means that expected value and gain amount are confounded (Ahn et al. 2008). Therefore, it is not possible to determine which of expected gains and expected value is responsible for the greater propensity of response learners in choosing disadvantageous decks.

\section{Set-shifting}

The WCST-64 results showing that response learners performed better during the task. While the role of the caudate nucleus in reversal learning is well supported, our results allows to better understand the impact of differences in the caudate nucleus function in the nonclinical population (Monchi et al. 2004, 2007; Nagano-Saito et al. 2008; MacDonald et al. 2014; Vaghi et al. 2017). This ability is of a particular practical importance for work performance, work ability, and decreased unemployment status in brain damaged patients (Kibby et al. 1998; Ready et al. 2001). Furthermore, substance use is associated with poor performance on the WCST (Ready et al. 2001). Since substance abuse was an exclusion factor in the present study, these results suggest that better performance on the WCST would be attributed to the response learners who do not engage in reward-seeking behaviors only. Further research on this topic could therefore be of interest.

Further, the lower task switch cost observed in response learners can also be attributed to the caudate nucleus, as it has previously been shown to be associated with increased action preparation (van Schouwenburg et al. 2010). While better task-switching abil- ities might allow for more efficiency when executing multiple tasks in parallel, it does not indicate that response learners multitask more often, as switch costs were previously found to be higher in frequent multitaskers (Ophir et al. 2009; Stoet et al. 2013). Therefore, we believe that the increased functional activity in the caudate nucleus observed in response learners is likely responsible for the increased reversal learning and action preparation abilities.

\section{Conclusion}

Our results suggest that caudate nucleusdependent response strategy, while being associated with increased risk-taking behavior, is also associated with increased set-shifting abilities.

Future steps would consist in a functional imaging study to better understand how the caudate nucleus can simultaneously affect navigation, decision-making, and set-shifting. At the moment, it is unclear if the same populations of caudate neurons are involved in these tasks, and why there would be such overlap. Also, a training study would be of interest to investigate the potential causal link between navigation and cognitive functions such as decision-making and set-shifting. A promising training program that trains participants to use the spatial strategy has already been developed, allowing such study to be performed (Andersen 2011). Future studies should also aim to use other tasks that measure risk-taking behavior that specifically separate gain frequency and expected value (Horstmann et al. 2012).

In conclusion, our findings show that response strategies can negatively affect cognitive functions in young adults as they are linked to increased risk-taking behavior. This supports previous

Spatial Learners $\square$ Response Learners

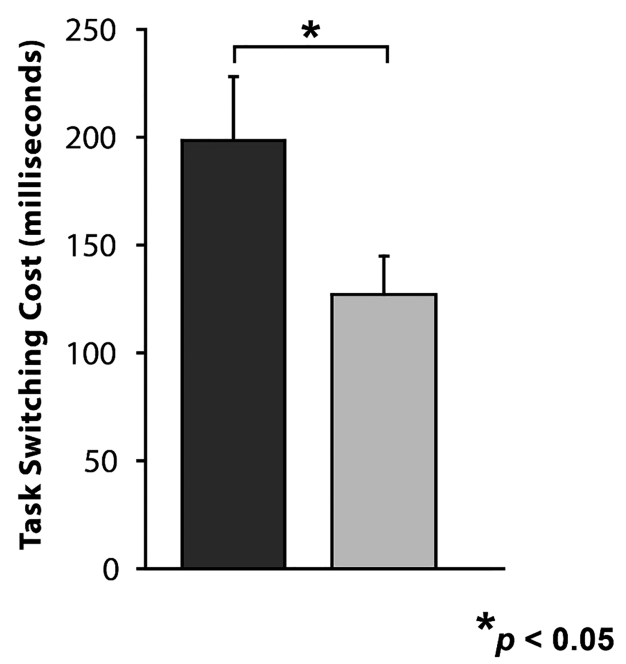

Figure 3. Results of task-switching test. Spatial learners displayed significantly higher reaction time cost when the trial rule was different from that of the previous trial. Error bars represent the standard errors. 
Part 1

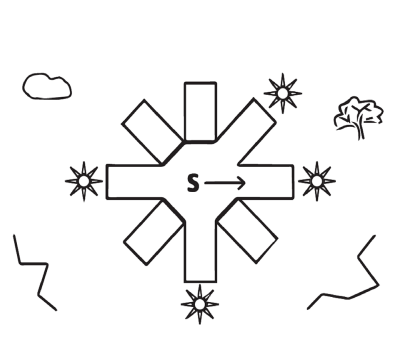

Probe Part 1

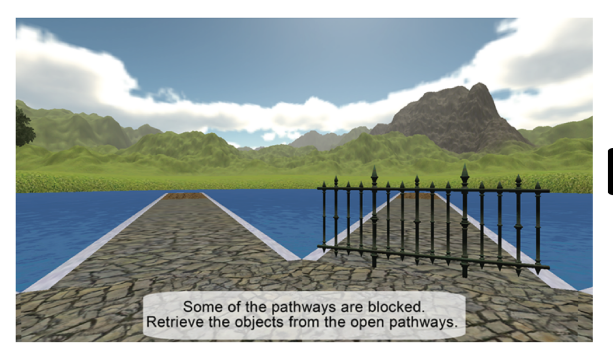

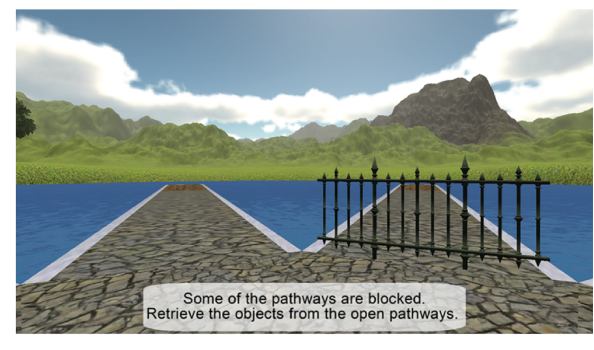

Part 2

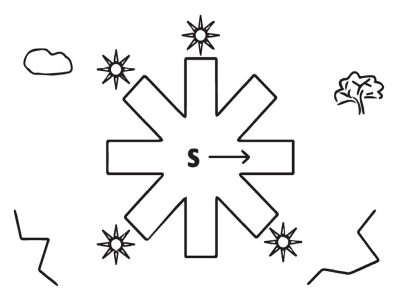

Probe Part 1

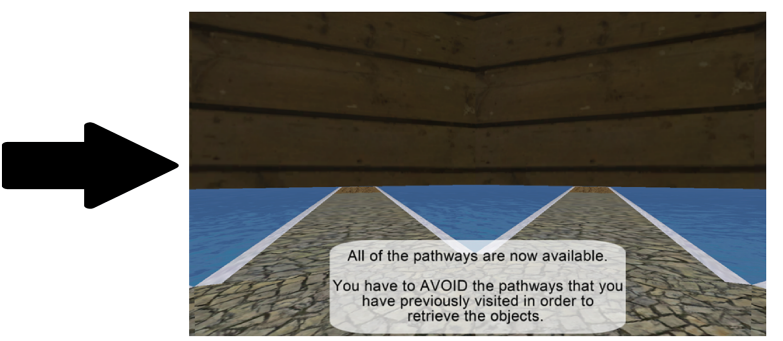

Figure 4. A view of the virtual environment used in the 4 on 8 virtual maze. Note the tree and mountains that form part of the landscape. A rock and meadow were also present in the virtual environment. In Part 1, participants retrieve four objects at the end of four available paths out of eight that extend from a central platform. In Part 2, participants remember which pathways they have already visited and avoid these in order to find the remaining objects. Probe: After acquisition, in Part 2, a wall is erected around the radial maze after learning, blocking the participants' view of landmarks in the environment.

studies where response learners were found to be more vulnerable to substance abuse and higher levels of action video game consumption (Bohbot et al. 2013; West et al. 2015, 2018). In parallel, a cognitive benefit of response learning was found in setshifting, which is an important executive function associated with increased cognitive flexibility. Future research should further study the costs and benefits associated with both response and spatial learning and link such differences in cognitive performance to functional and structural differences in the caudate nucleus and hippocampus.

\section{Materials and Methods}

\section{Participants}

Fifty-three participants (12 male) were recruited, with an age range of $18-35$ yr old $(M=23.98, S D=4.43 \mathrm{yr})$ and all having at least $14 \mathrm{yr}$ of education $(M=15.82, \mathrm{SD}=$ $1.91 \mathrm{yr})$. The study was approved by the University of Montreal Faculty of Arts and Science Ethics Committee and all participants gave their informed consent before participating. Participants were screened for psychiatric and neurological disorders and a history of substance abuse (Bohbot et al. 2007, 2013; Dahmani and Bohbot 2015; West et al. 2015, 2018; Konishi et al. 2017). Participants were nonsmokers who reported drinking less than 10 alcoholic drinks per month and not consuming other psychoactive drugs on a regular basis. No participants reported frequent video game playing, defined as a weekly use of at least $3 \mathrm{~h}$ per week for the last year. A monetary compensation equivalent to $15 \mathrm{CAD}$ per hour was

Net per 10 cards offered at the end of the study. Participants were recruited via word of mouth and ads posted on the Internet.

\section{4 on 8 virtual maze ( $4 / 8 \mathrm{VM})$}

The 4/8 VM was used in order to assess participants' spontaneous navigation strategy used when memorizing a novel environment (Fig. 4; Bohbot et al. 2007, 2013; Dahmani and Bohbot 2015; West et al. 2015, 2018; Konishi et al. 2017). This task places participants in the center of an eight-branched radial maze surrounded by landmarks - a tree, a rock, a mountain and a valley-each branch ending with a small pit in order to make it impossible to see whether or not an object is present at the end of the alley. The task is made of several trials, each divided into two parts. All landmarks are visible during Part 1 and Part 2 of each trial. This is then followed by a probe trial at the end of the task.
'Disadvantageous' Decks

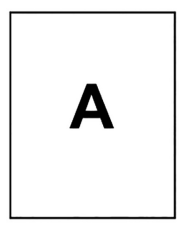

100

1250

$-250$

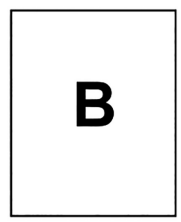

100

1250

$-250$
'Advantageous' Decks

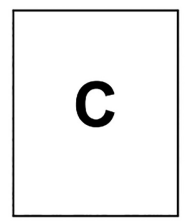

50

250

$+250$

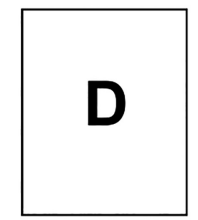

50

250

$+250$
Figure 5. Iowa Gambling Task. Four decks of cards are presented. Two cards are generally advantageous and two are generally disadvantageous. Participants have to choose 100 cards sequentially, where each card choice is followed by a display of both gains and losses. 


\section{Reference Cards}
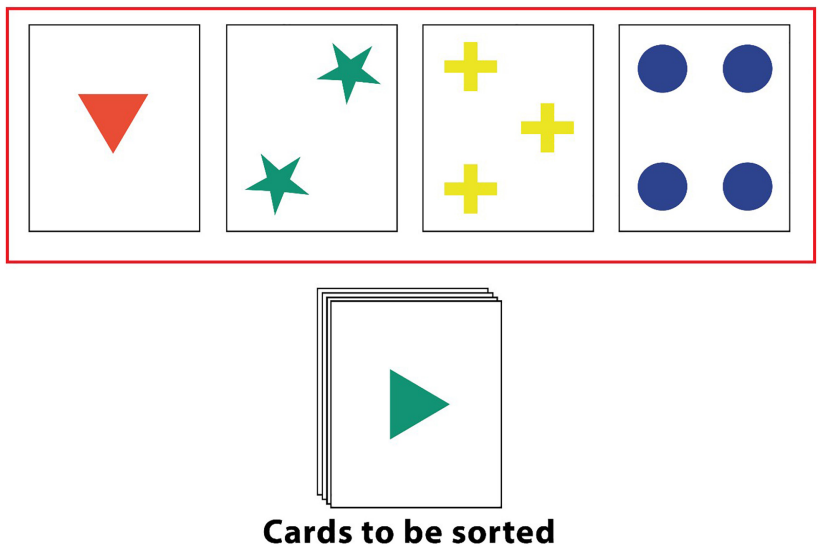

Figure 6. Wisconsin Card Sorting Test. Four reference cards, each with three unique characteristics, are placed on the table. The participant is given a deck of 64 cards. The participant associates the card on top with one of the four reference cards according to their characteristics. The valid sorting rule can be either according to the shape, the number of items on the card, the color of the item, or the figure of the item. The sorting rule changes as soon as the participant sort six cards correctly in a row.

Part 1: After having administrated instructions, the participant is placed in the center of the maze, always facing the same branch. Landmarks are visible, and four branches are blocked by barriers. The participant has to collect objects placed at the end of every open pathway.

Part 2: When ready, the participant can end Part 1 in order to be replaced in the center, facing the same initial pathway as in Part 1. The barriers have been removed and the participant has to collect all four remaining objects among the now opened branches.

Probe trial: When the participants has successfully completed a Part 2 without errors and has gone through at least three trials, the probe trial is triggered. If the criterion was not attained after eight trials, the task was terminated, and participants were removed from the study. Starting with a normal Part 1, it is followed by a unique Part 2 where the landscape has been hidden by walls. The probe trial perturbs performance uniquely in spatial learners who rely on the landmarks to navigate while not impacting response learners. Therefore, spatial learners display more probe errors than response learners (Bohbot et al. 2007, 2013; Dahmani and Bohbot 2015; West et al. 2015, 2018; Konishi et al. 2017).

After the probe trial, a final regular trial is administered. It is followed by a standardized interview in order to assess the spontaneous strategy used by the participant. They were asked to report how they knew which pathways contained objects and which were empty in the Part 2 trials. A description of the initial method of navigation during the very first trial was specifically asked, as it has previously been shown to be a reliable measure of initial spontaneous navigation strategy. Based on their description, participants were categorized as using either a spatial strategy or a response strategy (Bohbot et al. 2007, 2013; Dahmani and Bohbot 2015; West et al. 2015, 2018; Konishi et al. 2017). On the first trial, if participants reported using two or more landmarks to remember the location of the objects (e.g., going to the left of the tree, the two paths on the right of the rock and right in front of the mountain) and did not report using a sequence from a single starting point, they were categorized as spatial learners. If the participant reported using a sequence or pattern, counting from a single starting point (e.g., counting pathways starting from the tree, and then selecting Paths $1,3,5$, and 6) to remember the locations of the objects, they were categorized as response learners (Iaria et al. 2003; Bohbot et al. 2007, 2013; Andersen 2011; Dahmani and Bohbot 2015; West et al. 2015, 2018; Drisdelle et al. 2017; Aumont et al. 2019). lowa Gambling Task

In this task first described by Bechara et al. (1994), four decks of cards are presented, from which a total 100 cards have to be chosen (Fig. 5). Instructions are standardized and inform that the goal is to maximize money obtained in the game. After each card selected, both gains and losses are displayed to the participant. The first two decks are considered advantageous, whereas the last two decks are disadvantageous. The first one is associated with $\$ 50$ gains on every card and $50 \%$ chances of $\$ 50$ losses, therefore never causing any losses. The second grants $\$ 50$ gains on every card with $10 \%$ chances of $\$ 250$ losses. The third deck provides $\$ 100$ gains on every card with $10 \%$ chances of $\$ 1250$ losses. The last deck grants $\$ 100$ reward on every card with $50 \%$ of losses scaling from $\$ 150$ to $\$ 350$. The raw score is calculated as the amount of money held at the end of the task, whereas the net score is calculated by subtracting the number of advantageous cards selected with the number of disadvantageous cards selected. Learning can be characterized by splitting the task into five 20 -trial blocks, each described by their net subscores.

\section{Wisconsin Card Sorting Test}

In the WCST-64, four reference cards are placed on the table in front of the participant (Fig. 6). Each card is a set of three unique characteristics: one red triangle, two green stars, three yellow crosses, and four blue circles. The participant is asked to match the card on the top of his 64-card deck with one of the four reference cards. The experimenter responds by saying "yes" if the match follows the current rule and "no" if it does not. The cards can be matched according to three possible rules: shape, number, or color. The rule is changed once the participant has correctly matched cards six times in a row. Rules are changed up to five times, from color to shape to number to color to shape and to number. The task is over once the last rule is completed (task completed) or once all 64 cards have been used (task not completed). Perseveration errors are a type of error where the participant insists on trying to match cards according to an invalid rule several times (see Greve 2001 for details).

A
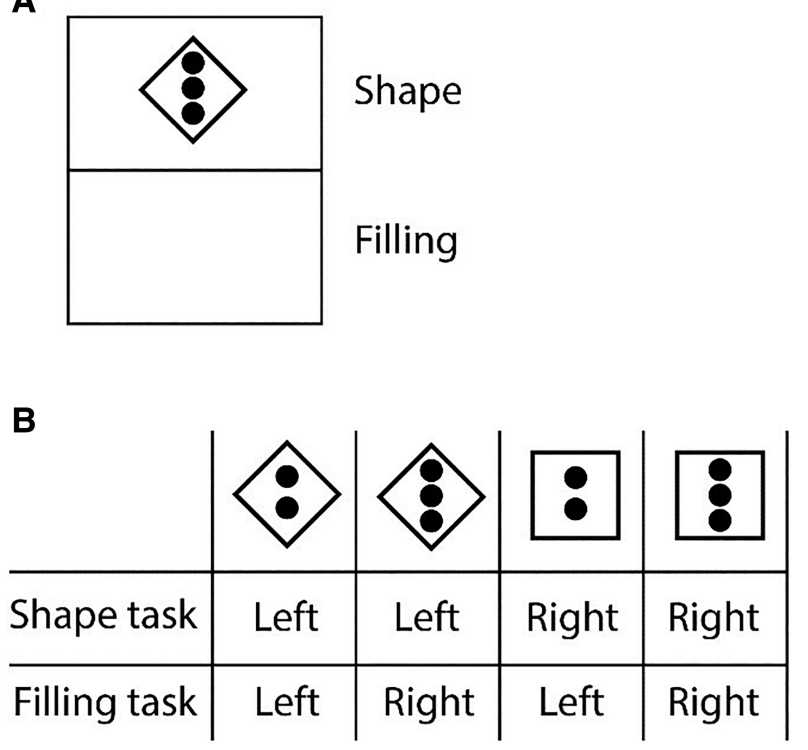

Figure 7. Stimuli used in the task-switching test. $(A)$ Representation of the stimulus display for a single trial: a figure appears either on the top or bottom part of the screen. When it appears in the top, the correct response depends on the shape of the stimulus, whereas when it is presented in the bottom, it depends on the number of points inside the figure. (B) Stimuli are either squares or diamonds with either two or three points inside. Possible responses associated with each of the four stimuli are displayed for both top and bottom conditions. 


\section{Task-switching}

Task-switching was used as a measure of reaction time cost for a predictable rule change. The task was inspired by the description in Stoet et al. (2013), where either squares or diamonds filled with either two or three points are presented (Fig. 7). The participant had to answer according to either the figure's shape or filling, depending on its spatial position. The bottom of the screen was associated with following the filling rule, whereas the top of the screen was associated with the shape rule. The task was divided in three practice blocks and three data collection blocks following the same sequence. The first block exclusively used the shape task, the second exclusively used the filling task, and the third block used the alternate run paradigm, where both tasks alternated every two trials so that one trial out of two was characterized by a change of rule, while the other was not (e.g., SSFFSSFFSSFF) (Monsell 2003). Block length are respectively 10,10 , and 20 trials for the practice blocks and 40, 40, and 80 trials for the data collection blocks. Calculation of the switch cost was made by subtracting response time in rule change trials to no rule change trials in the alternating block.

\section{Acknowledgments}

The funding source for this paper is Natural Sciences and Engineering Research Council of Canada Discovery grant number 436140-2013.

\section{References}

Aarts E, Nusselein AAM, Smittenaar P, Helmich RC, Bloem BR, Cools R. 2014. Greater striatal responses to medication in Parkinson's disease are associated with better task-switching but worse reward performance. Neuropsychologia 62: 390-397. doi:10.1016/j.neuropsychologia.2014.05 .023

Ahn WY, Busemeyer JR, Wagenmakers EJ, Stout JC. 2008. Comparison of decision learning models using the generalization criterion method. Cogn Sci 32: 1376-1402. doi:10.1080/03640210802352992

Andersen NE. 2011. Spatial memory training program: using virtual reality as a tool to provide spatial memory training. McGill University, Montréal.

Aumont E, Bohbot VD, West GL. 2019. Spatial learners display enhanced oculomotor performance. J Cogn Psychol 30: 872-879. https://doi.org/10 $.1080 / 20445911.2018 .1526178$

Baler RD, Volkow ND. 2006. Drug addiction: the neurobiology of disrupted self-control. Trends Mol Med 12: 559-566. doi:10.1016/j.molmed.2006 .10 .005

Balleine BW, Delgado MR, Hikosaka O. 2007. The role of the dorsal striatum in reward and decision-making. J Neurosci 27: 8161-8165. doi:10.1523/ JNEUROSCI.1554-07.2007

Bechara A, Damasio AR, Damasio H, Anderson SW. 1994. Insensitivity to future consequences following damage to human prefrontal cortex. Cognition 50: 7-15. doi:10.1016/0010-0277(94)90018-3

Bohbot VD, Iaria G, Petrides M. 2004. Hippocampal function and spatial memory: evidence from functional neuroimaging in healthy participants and performance of patients with medial temporal lobe resections. Neuropsychology 18: 418-425. doi:10.1037/0894-4105.18.3 .418

Bohbot VD, Lerch J, Thorndycraft B, Iaria G, Zijdenbos AP. 2007. Gray matter differences correlate with spontaneous strategies in a human virtual navigation task. J Neurosci 27: 10078-10083. doi:10.1523/ JNEUROSCI.1763-07.2007

Bohbot VD, Del Balso D, Conrad K, Konishi K, Leyton M. 2013. Caudate nucleus-dependent navigational strategies are associated with increased use of addictive drugs: substance abuse and spatial memory. Hippocampus 23: 973-984. doi:10.1002/hipo.22187

Brody AL, Mandelkern MA, Olmstead RE, Scheibal D, Hahn E, Shiraga S, Zamora-Paja E, Farahi J, Saxena S, London ED, et al. 2006. Gene variants of brain dopamine pathways and smoking-induced dopamine release in the ventral caudate/nucleus accumbens. Arch Gen Psychiatry 63: 808816. doi:10.1001/archpsyc.63.7.808

Buelow MT, Blaine AL. 2015. The assessment of risky decision making: a factor analysis of performance on the Iowa Gambling Task, Balloon Analogue Risk Task, and Columbia Card Task. Psychol Assess 27: 777785. doi: $10.1037 / \mathrm{a} 0038622$

Buelow MT, Suhr JA. 2009. Construct validity of the Iowa Gambling Task. Neuropsychol Rev 19: 102-114. doi:10.1007/s11065-009-9083-4
Callesen MB, Hansen KV, Gjedde A, Linnet J, Møller A. 2013. Dopaminergic and clinical correlates of pathological gambling in Parkinson's disease: a case report. Front Behav Neurosci 7: 295. doi:10.3389/fnbeh.2013.00095

Cohen J. 1977. Statistical power analysis for the behavioral sciences, Revised edition. Academic Press, New York.

Cools R. 2006. Dopaminergic modulation of cognitive function-implications for l-DOPA treatment in Parkinson's disease. Neurosci Biobehav Rev 30: 1-23. doi:10.1016/j.neubiorev.2005.03.024

Cools R. 2011. Dopaminergic control of the striatum for high-level cognition. Curr Opin Neurobiol 21: 402-407. doi:10.1016/j.conb.2011 .04 .002

Cools R, D'Esposito M. 2011. Inverted-U-shaped dopamine actions on human working memory and cognitive control. Biol Psychiatry 69: e113-e125. doi:10.1016/j.biopsych.2011.03.028

Cools R, Barker RA, Sahakian BJ, Robbins TW. 2001. Enhanced or impaired cognitive function in Parkinson's disease as a function of dopaminergic medication and task demands. Cereb Cortex 11: 1136-1143. doi:10 .1093/cercor/11.12.1136

Cools R, Barker RA, Sahakian BJ, Robbins TW. 2003. 1-Dopa medication remediates cognitive inflexibility, but increases impulsivity in patients with Parkinson's disease. Neuropsychologia 41: 1431-1441. doi:10.1016/ S0028-3932(03)00117-9

Dahmani L, Bohbot VD. 2015. Dissociable contributions of the prefrontal cortex to hippocampus- and caudate nucleus-dependent virtual navigation strategies. Neurobiol Learn Mem 117: 42-50. doi:10.1016/j .nlm.2014.07.002

Doeller CF, King JA, Burgess N. 2008. Parallel striatal and hippocampal systems for landmarks and boundaries in spatial memory. Proc Natl Acad Sci 105: 5915-5920. doi:10.1073/pnas.0801489105

Drisdelle BL, Konishi K, Diarra M, Bohbot VD, Jolicoeur P, West GL. 2017. Electrophysiological evidence for enhanced attentional deployment in spatial learners. Exp Brain Res 235: 1387-1395. doi:10.1007/ s00221-017-4884-9

Everitt BJ, Robbins TW. 2005. Neural systems of reinforcement for drug addiction: from actions to habits to compulsion. Nat Neurosci 8: 14811489. doi:10.1038/nn1579

Frank MJ, Samanta J, Moustafa AA, Sherman SJ. 2007. Hold your horses: impulsivity, deep brain stimulation, and medication in Parkinsonism. Science 318: 1309-1312. doi:10.1126/science.1146157

Gardner RS, Gold PE, Korol DL. 2018. A multiple memory systems approach to understanding cognitive aging: not all aging is equal. Soc Neurosci https://abstractsonline.com/pp8/\#!/4649/presentation/11717.

Goodman J, Packard MG. 2016. Memory systems and the addicted brain. Front Psychiatry 7: 24. doi:10.3389/fpsyt.2016.00024

Greve KW. 2001. The WCST-64: a standardized short-form of the Wisconsin Card Sorting Test. Clin Neuropsychol 15: 228-234. doi:10.1076/clin.15.2 .228 .1901

Gul A, Yousaf J, Ahmad H. 2017. Frontal-subcortical defects correlate with task switching deficits in Parkinson's disease. Neurosciences 22: 224-227. doi:10.17712/nsj.2017.3.20160572

Hayes AE, Davidson MC, Keele SW, Rafal RD. 1998. Toward a functional analysis of the basal ganglia. J Cogn Neurosci 10: 178-198. doi:10.1162/ 089892998562645

Horstmann A, Villringer A, Neumann J. 2012. Iowa Gambling Task: there is more to consider than long-term outcome. Using a linear equation model to disentangle the impact of outcome and frequency of gains and losses. Front Neurosci 6: 61. doi:10.3389/fnins.2012.00061

Iaria G, Petrides M, Dagher A, Pike B, Bohbot VD. 2003. Cognitive strategies dependent on the hippocampus and caudate nucleus in human navigation: variability and change with practice. J Neurosci 23: 59455952. doi:10.1523/JNEUROSCI.23-13-05945.2003

Johnson A, van der Meer MA, Redish AD. 2007. Integrating hippocampus and striatum in decision-making. Curr Opin Neurobiol 17: 692-697. doi:10.1016/j.conb.2008.01.003

Kibby MY, Schmitter-Edgecombe M, Long CJ. 1998. Ecological validity of neuropsychological tests: focus on the California Verbal Learning Test and the Wisconsin Card Sorting Test. Arch Clin Neuropsychol 13: 523534. doi:10.1093/arclin/13.1.77

Konishi K, Bohbot VD. 2013. Spatial navigational strategies correlate with gray matter in the hippocampus of healthy older adults tested in a virtual maze. Front Aging Neurosci 5: 1. doi:10.3389/fnagi.2013.00001

Konishi K, Mckenzie S, Etchamendy N, Roy S, Bohbot VD. 2017. Hippocampus-dependent spatial learning is associated with higher global cognition among healthy older adults. Neuropsychologia 106: 310-321. doi:10.1016/j.neuropsychologia.2017.09.025

Lee AS, Duman RS, Pittenger C. 2008. A double dissociation revealing bidirectional competition between striatum and hippocampus during learning. Proc Natl Acad Sci 105: 17163-17168. doi:10.1073/pnas .0807749105

Lerch JP, Yiu AP, Martinez-Canabal A, Pekar T, Bohbot VD, Frankland PW, Henkelman RM, Josselyn SA, Sled JG. 2011. Maze training in mice induces MRI-detectable brain shape changes specific to the type of 
learning. Neuroimage 54: 2086-2095. doi:10.1016/j.neuroimage.2010 .09 .086

MacDonald AA, Seergobin KN, Tamjeedi R, Owen AM, Provost JS, Monchi O, Ganjavi H, MacDonald PA. 2014. Examining dorsal striatum in cognitive effort using Parkinson's disease and fMRI. Ann Clin Transl Neurol 1: $390-400$. doi:10.1002/acn3.62

Milner B. 1963. Effects of different brain lesions on card sorting: the role of the frontal lobes. Arch Neurol 9: 90-100. doi:10.1001/archneur.1963 .00460070100010

Monchi O, Petrides M, Petre V, Worsley K, Dagher A. 2001. Wisconsin Card Sorting revisited: distinct neural circuits participating in different stages of the task identified by event-related functional magnetic resonance imaging. J Neurosci 21: 7733-7741. doi:10.1523/JNEUROSCI .21-19-07733.2001

Monchi O, Petrides M, Doyon J, Postuma RB, Worsley K, Dagher A. 2004. Neural bases of set-shifting deficits in Parkinson's disease. J Neurosci 24: 702-710. doi:10.1523/JNEUROSCI.4860-03.2004

Monchi O, Petrides M, Strafella AP, Worsley KJ, Doyon J. 2006. Functional role of the basal ganglia in the planning and execution of actions. Ann Neurol 59: 257-264. doi:10.1002/ana.20742

Monchi O, Petrides M, Mejia-Constain B, Strafella AP. 2007. Cortical activity in Parkinson's disease during executive processing depends on striatal involvement. Brain 130: 233-244. doi:10.1093/brain/awl326

Monsell S. 2003. Task switching. Trends Cogn Sci 7: 134-140. doi:10.1016/ S1364-6613(03)00028-7

Müller NCJ, Konrad BN, Kohn N, Muñoz-López M, Czisch M, Fernández G, Dresler M. 2018. Hippocampal-caudate nucleus interactions support exceptional memory performance. Brain Struct Funct 223: 1379-1389. doi:10.1007/s00429-017-1556-2

Nagano-Saito A, Leyton M, Monchi O, Goldberg YK, He Y, Dagher A. 2008. Dopamine depletion impairs frontostriatal functional connectivity during a set-shifting task. J Neurosci 28: 3697-3706. doi:10.1523/ JNEUROSCI.3921-07.2008

O'Keefe J, Nadel L. 1978. The hippocampus as a cognitive map. Clarendon Press/Oxford University Press, New York/Oxford.

Ophir E, Nass C, Wagner AD. 2009. Cognitive control in media multitaskers. Proc Natl Acad Sci 106: 15583-15587. doi:10.1073/pnas.0903620106

Packard MG. 1999. Glutamate infused posttraining into the hippocampus or caudate-putamen differentially strengthens place and response learning. Proc Natl Acad Sci 96: 12881-12886. doi:10.1073/pnas.96.22 .12881

Packard MG, Knowlton BJ. 2002. Learning and memory functions of the basal ganglia. Anпu Rev Neurosci 25: 563-593. doi:10.1146/annurev .neuro.25.112701.142937

Poldrack RA, Clark J, Paré-Blagoev EJ, Shohamy D, Creso Moyano J, Myers C, Gluck MA. 2001. Interactive memory systems in the human brain. Nature 414: $546-550$. doi:10.1038/35107080

Provost JS, Petrides M, Simard F, Monchi O. 2012. Investigating the long-lasting residual effect of a set shift on frontostriatal activity. Cereb Cortex 22: 2811-2819. doi:10.1093/cercor/bhr358

Rangel A, Camerer C, Montague PR. 2008. A framework for studying the neurobiology of value-based decision making. Nat Rev Neurosci 9: 545556. doi:10.1038/nrn2357

Ready RE, Stierman L, Paulsen JS. 2001. Ecological validity of neuropsychological and personality measures of executive functions. Clin Neuropsychol 15: 314-323. doi:10.1076/clin.15.3.314.10269

Reynolds EK, Collado-Rodriguez A, MacPherson L, Lejuez C. 2013. Chapter 21 - impulsivity, disinhibition, and risk taking in addiction. In Principles of addiction (ed. Miller PM), pp. 203-212. Academic Press, San Diego, CA.

Robbins TW, Everitt BJ. 2002. Limbic-striatal memory systems and drug addiction. Neurobiol Learn Mem 78: 625-636. doi:10.1006/nlme.2002 .4103
Rogers RD, Andrews TC, Grasby PM, Brooks DJ, Robbins TW. 2000. Contrasting cortical and subcortical activations produced by attentional-set shifting and reversal learning in humans. J Cogn Neurosci 12: $142-162$. doi:10.1162/089892900561931

Samejima K, Ueda Y, Doya K, Kimura M. 2005. Representation of action-specific reward values in the striatum. Science 310: 1337-1340. doi:10.1126/science. 1115270

Shi Y, Wolfensteller U, Schubert T, Ruge H. 2018. When global rule reversal meets local task switching: the neural mechanisms of coordinated behavioral adaptation to instructed multi-level demand changes. Hum Brain Mapp 39: 735-746. doi:10.1002/hbm.23878

Shohamy D, Turk-Browne NB. 2013. Mechanisms for widespread hippocampal involvement in cognition. J Exp Psychol Gen 142: 11591170. doi:10.1037/a0034461

Shohamy D, Wagner AD. 2008. Integrating memories in the human brain: hippocampal-midbrain encoding of overlapping events. Neuron 60: 378-389. doi:10.1016/j.neuron.2008.09.023

Stoet G, O'Connor DB, Conner M, Laws KR. 2013. Are women better than men at multi-tasking? BMC Psychol 1: 18. doi:10.1186/2050-7283-1-18

Vaghi MM, Vértes PE, Kitzbichler MG, Apergis-Schoute AM, van der Flier FE, Fineberg NA, Sule A, Zaman R, Voon V, Kundu P, et al. 2017. Specific frontostriatal circuits for impaired cognitive flexibility and goal-directed planning in obsessive-compulsive disorder: evidence from resting-state functional connectivity. Biol Psychiatry 81: 708-717. doi:10.1016/j .biopsych.2016.08.009

van Schouwenburg MR, den Ouden HE, Cools R. 2010. The human basal ganglia modulate frontal-posterior connectivity during attention shifting. J Neurosci 30: 9910-9918. doi:10.1523/JNEUROSCI.1111-10 .2010

Vo LTK, Walther DB, Kramer AF, Erickson KI, Boot WR, Voss MW, Prakash RS, Lee H, Fabiani M, Gratton G, et al. 2011. Predicting individuals' learning success from patterns of pre-learning MRI activity PLoS One 6: e16093. doi:10.1371/journal.pone.0016093

Voermans NC, Petersson KM, Daudey L, Weber B, van Spaendonck KP, Kremer HPH, Fernández G. 2004. Interaction between the human hippocampus and the caudate nucleus during route recognition. Neuron 43: 427-435. doi:10.1016/j.neuron.2004.07.009

Volkow ND, Fowler JS, Wang GJ, Swanson JM, Telang F. 2007. Dopamine in drug abuse and addiction: results of imaging studies and treatment implications. Arch Neurol 64: 1575. doi:10.1001/archneur.64.11.1575

West GL, Drisdelle BL, Konishi K, Jackson J, Jolicoeur P, Bohbot VD. 2015. Habitual action video game playing is associated with caudate nucleus-dependent navigational strategies. Proc R Soc B Biol Sci 282: 20142952. doi:10.1098/rspb.2014.2952

West GL, Konishi K, Diarra M, Benady-Chorney J, Drisdelle BL, Dahmani L, Sodums DJ, Lepore F, Jolicoeur P, Bohbot VD. 2018. Impact of video games on plasticity of the hippocampus. Mol Psychiatry 23: 1566-1574 doi:10.1038/mp.2017.155

Wimmer GE, Shohamy D. 2012. Preference by association: how memory mechanisms in the hippocampus bias decisions. Science 338: 270-273. doi:10.1126/science.1223252

Wimmer GE, Braun EK, Daw ND, Shohamy D. 2014. Episodic memory encoding interferes with reward learning and decreases striatal prediction errors. J Neurosci 34: 14901-14912. doi:10.1523/JNEUROSCI 0204-14.2014

Wylie G, Allport A. 2000. Task switching and the measurement of "switch costs". Psychol Res 63: 212-233. doi:10.1007/s004269900003

Received August 27, 2018; accepted in revised form February 7, 2019. 


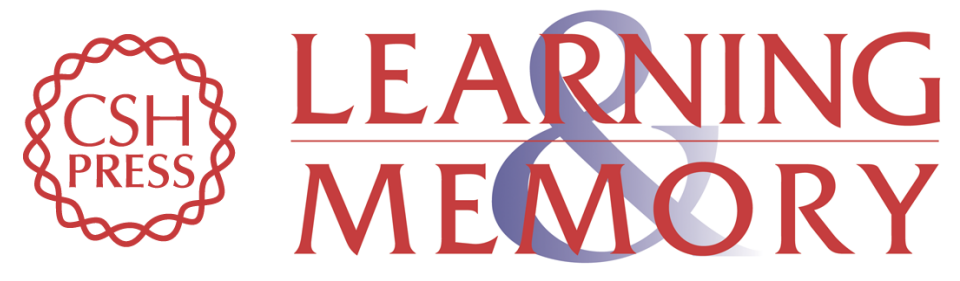

\section{Caudate nucleus-dependent navigation strategies are associated with increased risk-taking and set-shifting behavior}

Étienne Aumont, Caroll-Ann Blanchette, Veronique D. Bohbot, et al.

Learn. Mem. 2019, 26:

Access the most recent version at doi:10.1101/lm.048306.118

References This article cites 68 articles, 15 of which can be accessed free at: http://learnmem.cshlp.org/content/26/4/101.full.html\#ref-list-1

Creative This article is distributed exclusively by Cold Spring Harbor Laboratory Press for the Commons first 12 months after the full-issue publication date (see

License http://learnmem.cshlp.org/site/misc/terms.xhtml). After 12 months, it is available under a Creative Commons License (Attribution-NonCommercial 4.0 International), as described at http://creativecommons.org/licenses/by-nc/4.0/.

Email Alerting Receive free email alerts when new articles cite this article - sign up in the box at the Service top right corner of the article or click here. 